\title{
ORIBATID MITES (ACARI: ORIBATIDA) IN MICROCOSMS - A REVIEW
}

\author{
Gergócs, V. ${ }^{1} *$ - HUfNAGEL, L. ${ }^{2}$ \\ ${ }^{1}$ Eötvös Loránd University, Department of Plant Taxonomy and Ecology \\ H-1117 Budapest, Pázmány Péter sétány 1/C, Hungary \\ ${ }^{2}$ Corvinus University of Budapest, Department of Mathematics and Informatics \\ H-1118 Budapest, Villányi út 29-43, Hungary \\ (phone: +36-1-294-9875) \\ *Corresponding author \\ e-mail:veragergocs@gmail.com \\ (Received $13^{\text {th }}$ November 2011; accepted $2^{\text {nd }}$ December 2011)
}

\begin{abstract}
Oribatid mites are one of the most abundant and species rich group in soil mesofauna. In spite of this, we have limited knowledge on the role they play in ecological processes. Since they are small like other mesofauna members and live a hidden life, their observation is difficult. Their life style, interactions with other organisms and role in soil decomposition processes can be investigated with laboratory experiments more exactly and effectively. While the literature of microcosm studies is very extensive, relatively few review papers have been written about the methodology of microcosm studies. The present review summarizes details of techniques that have been applied laboratory microcosms involving oribatid mites. It is shown what one should keep in mind in planning, composing and setting up a microcosm. Our comparative evaluation reveals how the laboratory experiments were maintained and manipulated and what kind of information was extracted. This methodological review can be useful in preparing microcosm experiments applied to other animal groups as well.
\end{abstract}

Keywords: ecosystem, community ecology, microcosms, mesofauna, soil ecology, methodology

\section{Introduction}

Oribatid mites are one of the most abundant and species rich mesofauna group particularly in temperate deciduous forests and boreal coniferous forests (Wallwork, 1983). They occur almost in every type of terrestrial (and in some freshwater) habitat of the world, in all kinds of microhabitats, and for this reason they can have great significance in the area of indication researches (Balogh et al, 2008; Gergócs and Hufnagel 2009; Gergócs et al, 2010, 2011).

Most of the species are generalists regarding feeding mode and habitat preference (Maraun et al., 2007), a large part of the species feed on saprotrophic fungi but there are also bacteria feeders, detritivorous species and some of them feed on carrion (BehanPelletier, 1999). However, many questions have remained unanswered in oribatid ecology. Despite their large density and species richness, we still do not know the answers to the following questions: why are they so diverse, what kind of interactions they have with other soil dweller animals and microorganisms, what kind of role they play in decomposition, do they facilitate or obstruct mineralization, etc.. Since oribatid mites are small animals (the largest species are about $1 \mathrm{~mm}$ long) they are difficult to observe directly. Even Wallwork (1983) suggested that they should be studied in microcosms.

Accordingly, many studies related to oribatid mites have been performed in laboratory microcosms. By definition, microcosms are ,miniature constructed 
ecosystems in which physical and biological constrains are imposed to enable the controlled study of ecological processes" (Drake and Kramer, 2011), or formulating briefly: „small ecosystems in containers” (Fraser and Keddy, 1997), or „enclosed model ecosysterms" (Kampichler et al., 2001). The latter study emphasized that all the microcosm experiments are performed in laboratory under artificial circumstances and they should not be confused with mesocosms, which are „bounded and partially enclosed outdoor experimental set-ups, that is, field enclosures with reduced or controlled input and output from and to its surrounding environment". The scientific relevance of microcosm experiments is controversial, both camps (pro and contra microcosms) present several arguments in favor of their opinions. The critical comments against microcosms were divided into three groups by Drake and Kramer (2011): 1. Microcosms are ecologically too simple and the results coming from simplified processes cannot be extrapolated to nature. 2. Microcosms are too small and the experiments are too short in time so they cannot reflect realistic spatial and temporal changes. 3. The results of this kind of experiments are only valid under artificial circumstances. Nevertheless, microcosm experiments have many advantages because they are relative cheap, easy to carry out, they can be done close to the researchers' workplace, they can be controlled easily and the constraints can be set exactly. The above mentioned problems are not necessarily drawbacks because complex natural processes often cannot be studied in intact state, microcosms can separate mechanisms and therefore we can test our theories after simplification more effectively (Drake and Kramer, 2011).

Most of the organisms living in soil and taking part in decomposition processes are small and cannot be investigated with naked eye. This explains why microcosm experiments have been conducted since the 1960s (Huhta, 2007). It is advantageous to use mini ecosystem experiments to examine processes taking place in soil because they can be studied easily under laboratory circumstances thanks to their small size and short generation time of the soil biota. In addition, microcosms are good models for recognizing interactions among organisms living in soil (Moore et al., 1996).

The compilation of microcosms is a difficult procedure. We must pay attention to many factors if we want to imitate nature under artificial circumstances. We have to decide on the kinds of organisms to be included, and the environment to be ensured. Life conditions of microorganisms, animals and at times plants must be created in such a way that the processes we want to examine will not be bothered by anything. Microcosm experiments last comparatively long therefore the adequate circumstances (e.g. humidity) must be monitored and maintained for long time as well. Finally, data collection is also an important aspect, because it must reflect the changes taking place during the experiment.

Microcosm studies have been reviewed by many articles analysing the results in many aspects (e.g. Fraser and Keddy, 1996) except for methodological ones. The aim of this study is to compensate this gap. Microcosm experiments are very extensive and are applied in many fields of science, so their set-up is also different. Therefore, we have narrowed down the issue of our review to the part of soil ecology related to oribatid mites kept in microcosms. Since these mites are in connection with many other soildwelling organisms, the methods we discuss in this paper can be useful not only for studying oribatid mites but for examining other faunal groups as well.

The experiments are very diverse even in this narrower field. At first, we demonstrate what kinds of problems have been approached with laboratory microcosms. 
Then, we discuss to what we pay attention during composing and keeping a microcosm. In this part of the paper, we summarize the methods that were used in 46 publications we have included in this review. We suggest that any microcosm experiment can be divided into three phases. The first one is setting up the microcosm itself, planning the experiment and setting the starting conditions. The second one is incubation when the system runs according to the initial settings. The third phase is the extraction of information. The construction of this paper follows the above sections.

\section{Objectives of microcosm studies}

There are many research issues related to microcosms including oribatid mites. One of them concerns the effect of temperature on oribatid species or communities. Uvarov(2003) showed that Nothrus silvestris Nicolet, 1855 living in temperate deciduous forests survives large temperature changes $\left(5-25^{\circ} \mathrm{C}\right)$. Temperature tolerance of five other species was studied by Deere et al. (2006) in microcosms. Søvic and Leinaas (2003) monitored the changes of artificially composed populations of Ameronothrus lineatus Thorell, for several years in laboratory. This microcosm experiment made possible that the density changes of the specimens in different life history stages could be examined according to the seasonal fluctuations of temperature. In other studies, the effects of changing temperature on soil dwelling mesofauna and on decomposition processes were analysed. In these papers (e.g. Sulkava and Huhta, 2003) it was revealed that little temperature fluctuations around freezing point $\left(-2{ }^{\circ} \mathrm{C}\right.$ and $+2{ }^{\circ} \mathrm{C}$ ) had minor effects on oribatid communities in boreal and subarctic habitats (Sulkava and Huhta 2003; Sjursen et al. 2005). Only extreme freeze caused greater loss of abundance of certain species (Sulkava and Huhta, 2003).

The behaviour of specimens can be investigated more effectively under controlled conditions. Such behaviour is, for example, the running and migration speed of small animals, which was measured either for each specimen on a paper sheet with a frame of $1-\mathrm{mm}^{2}$ or with a whole animal community in their natural microhabitat. As measured on a paper sheet, speed was very different over oribatida species because the specimens covered $1 \mathrm{~cm}$ distance in 10-100 s (Smrž, 2006). When migration of species was analysed in their natural substrates, it was revealed that species living in litter layer migrated faster than those living in soil but there were also great differences between speed values (Ojala and Huhta, 2001). Domes et al. (2007) carried out a similar experiment by comparing migration speed of sexual and parthenogenetic oribatid mites but they could not reveal any difference between the migration ability of the two groups.

Studying the feeding of oribatid mites has already been approached from many aspects. Some of the laboratory experiments involve food preference examinations when the animals are generally kept on artificial substrates (e.g. wet plaster of Paris and charcoal) and they are offered various kinds of food. Quality of consumed food is determined from the decrease of food and from gut content examinations (e.g. Smrž, 2006). In other cases, animals are offered special food in a microcosm filled with natural substrates. Remén et al. (2010) and Crowther et al. $(2005,2010)$ carried out soil microcosms with only one oribatid species and with a single micorrhiza or saprotrophic fungi species and the decrease of fungus biomass consumed by mites was monitored. Crotty et al. (2010) introduced bacteria enriched to 99 atom\% in ${ }^{13} \mathrm{C}$ and ${ }^{15} \mathrm{~N}$ to soil cores in laboratory and traced the flow of isotopes through the food web. They found that some of the oribatid mite species were enriched both in ${ }^{13} \mathrm{C}$ and ${ }^{15} \mathrm{~N}$, reflecting that 
these species are bacterial feeders. Besides feeding habits, competition between oribatid species can also be examined under laboratory conditions. Anderson (1978) demonstrated in a microcosm experiment that Nothrus silvestris and Hermanniella granulata Nicolet, 1855 compete with each other because the presence of both species in mini ecosystems affected their feeding and distribution over microcosm layers.

Until recently, the role of oribatid mites in soil decomposition processes has not been clarified completely. There are some microcosm studies examining the role of oribatid mites in decomposition of given plant materials. Wickings and Grandy (2011) traced the role of Scheloribates moestus, Banks 1895 in litter decomposition of red oak (Quercus rubra, L. 1753) and corn (Zea mays, L. 1753). They found that the presence of mite specimens influenced corn litter chemistry: mineralization of $\mathrm{C}$ and $\mathrm{N}$ and extracellular enzyme activities increased. Siepel and Maaskamp (1994) investigated several species belonging to different feeding guilds. They found that fungivorous grazer species (e.g. Nothrus silvestris) indirectly stimulated decomposition: saprotrophic fungi could grow faster because of the great amount of $\mathrm{N}$ released from fungal cell-walls by grazing.

The most extensive microcosm examinations including oribatid mites are related to the interactions among soil microorganisms, soil fauna and plants. There are many experiments where oribatid mites are categorised only as microarthropoda so this larger group is examined only as a whole. Accordingly, oribatid mites are not always discussed separately. In most experiments, the density of microarthropoda or their richness divided to greater groups (e.g. Cole et al., 2004), or the effect of their absence (e.g. Setälä and Huhta, 1991), or their interactions with earthworms (e.g. Adeyujigbe et al., 2006), with microorganisms (e.g. Liiri et al, 2002b), or with the primary production of plants and the mineralization processes (e.g. Cole et al., 2004) are studied. From these studies, we can get information only indirectly about the role of oribatid mites in given processes. If they are mentioned separately in such examinations, oribatid mites are reported not to have much effect on the studied functions (e.g. Setälä, 2000).

However, there are many other studies that discuss actual interactions between oribatid mites and other soil organisms. These studies examine, for example, the relationship between oribatid and predator mites. The results of these examinations generally show that most oribatid species are protected by their hard shell and are therefore not threatened by predators (e.g. Schneider and Maraun, 2009). Lopez et al. (2003, 2007) revealed that earthworms have negative effect on many oribatid mite species. Besides this, the oribatid mites and other microarthropoda can decrease the abundance of enchytraeids (Huhta et al., 1998). If oribatid mites' feeding on different fungus species is not studied directly, then their ability is investigated in facilitating reproduction and activities of soil fungi. Results showed that they can promote respiration and biomass production of soil fungi (Maraun et al., 1998).

Finally, there are studies on the effects of human impact on the environment (e.g. fragmentation, application of herbicides, pesticides, ash etc.) of soil mesofauna including oribatid mites. Rantalainen et al. (2004) and Staddon et al. (2010) established (micro)habitat islands or patches connected with corridors under laboratory conditions. The size of isolated (i.e. having no corridors) patches or islands was large enough for oribatid populations to increase during the incubation. Mixing natural substrates with ash is a more serious intervention. Liiri et al. (2002a) showed that application of wood ash in an acidophilous deciduous forest soil caused decrease in species number and density of oribatida communities. Heneghan and Bolger (1996) studied the effects of components of acid rain on soil fauna and found that application of potential pollutants 
of acid rain had impact on soil nutrient flow and decomposition processes, but different oribatid species responded in different ways, e.g. the populations of Oppiella nova Oudemans, 1902 did not change under nitric acid treatment.

The effects of sewage sludge on soil living organisms can also be examined in microcosms. Andres and Domene (2005) tested how sewage sludge treatment influenced soil communities. They found that different members of mesofauna responded to the various treatments of sewage sludge in different ways. Most of the groups of organisms suffered from the sludge only when it had been dried before adding to microcosms except for oribatid mites, whose density did not change considerably during the treatments. Pernin et al. (2005) tested the effects of sewage sludge with copper enrichment and found that the number of oribatid mites was decreased by the most serious treatment. Salminen et al. (1997) studied the effects of pentachlorophenol (PCP) on the structure of soil communities and on decomposition processes. This herbicide had direct or indirect negative effects on most of the organisms.

\section{Establishing a microcosm}

Many things must be considered while composing a microcosm since we want to imitate nature but a microcosm can only approximate its complexity. Laboratory microcosms can be stored in many kinds of containers. There are simple glass jars, plastic and glass cylinders, tailor-made boxes etc. Their size depends on the amount of substrates placed in them. In some studies, larger systems were created (e.g. Huhta and Setälä, 1990; Salminen and Sulkava, 1996) in which many other smaller microcosms were located. In these experiments not only the smaller microcosms were examined separately but the whole system and the interactions between the patches were also studied.

In case of containers, one must be careful that the microcosm dwelling organisms should not escape from the system and other animals should not come into the microcosm so all the mini ecosystems must be closed. Aeration is generally allowed by picking a hole or holes on the lid of containers which are closed with a cotton plug or with a gauze of a mesh size of $\sim 0,05-0,1 \mathrm{~mm}$. Other boxes are totally closed and there are some holes on them trough which constant air flow is maintained by a compressor (e.g. Huhta and Setälä, 1990). With the former method, air humidity can be kept constant and $\mathrm{CO}_{2}$-concentrations can be measured. In most of the cases, redundant water added to the system during the incubation must be left to flow out of the container. There are some studies in which the containers have a hole on their bottom for leaching water or a mesh is adjusted on the base of the container with open bottom (e.g. Andrés and Domene, 2005).

In most cases, humus and litter-layers of coniferous forest floor are placed into a microcosm of oribatid mites and other soil organisms. Out of the 46 reviewed publications 22 examined the soil fauna of coniferous forests, 8 papers were concerned with temperate deciduous forests and in the rest of the publications samples were taken from grasslands (e.g. Lopez et al., 2003), from agricultural fields (e.g. Adeyujigbe et al., 2006), and from subarctic fields (pl. Sjursen et al., 2005). Occasionally, animals were kept on artificial substrates (e.g. Fujikawa, 1999). We found coniferous forest floor substrate preference among the studies that examined plant seedlings and their interactions with soil animals and soil ecological processes because in ten out of 14 publications plant seedlings were planted into humus and litter substrate originated from coniferous forest floor. The amount of substrate applied in microcosms is very variable. 
In reference to studies applying coniferous forest floor, the microcosms mainly include humus and /or leaf litter but in half of these studies mineral soil is also layered under the above mentioned materials. This choice does not correlate with study objectives. The average dry mass of leaf litter ( $\mathrm{L}$ and/or F-layer) placed in microcosms is $5.7 \mathrm{~g}$ $(\mathrm{SD}=4.3)$, the average dry mass of humus (in some cases called as organic horizon) is 44.0g $(\mathrm{SD}=30.6)$. The applied amount of substrates did not depend on research objectives.

The substrates placed in microcosms are treated in many ways depending on the soil layer they originate from and on the purpose of the study. Treatments are usually made for homogenization and defaunation, i.e. killing almost all the living organisms in microhabitats collected from natural habitats. Mineral soil is generally sieved with 2-4 $\mathrm{mm}$ mesh and is washed with (warm) tap water to remove debris. In most of the cases, after mixing humus is sieved through a $1 \mathrm{~cm}$ mesh for homogenization, but after heating or drying it can be sieved even through 2-6 mm mesh. Leaf litter is often cut into pieces of $0.5-2 \mathrm{~cm}^{2}$ and there are some cases when litter material is washed with distilled water. Bigger twigs, roots and stone pieces are always removed from the substrates.

Before or after these treatments follows a more serious and more effective way of defaunation, which kills the whole biota or one part of the biota in a given sample. About three quarters of the investigated studies used some sort of defaunation. These methods are also very variable and cannot be linked exclusively to any study objective. The simplest defaunation method is drying but a more intensive method is heating. A wide range of temperatures (from $35{ }^{\circ} \mathrm{C}$ to $105{ }^{\circ} \mathrm{C}$ ) is applied for heating with a duration from 2.5 hours to 8 weeks. There are some methods for killing the animals with freeze: from $-18{ }^{\circ} \mathrm{C}$ to $-40{ }^{\circ} \mathrm{C}$; from 24 hours to 3 days. In other methods, temperature is changed between very low and very high values. Soil animals can be killed from the substrate also in a microwave oven.

The effectiveness and justification of applying a particular defaunation method have been rarely mentioned. Huhta et al. (1989) studied various defaunation methods and compared their effectiveness and side effects on soil fauna and soil characteristics. Repeated microwaving ( $380 \mathrm{~W}, 3$ minutes) and repeated freezing-thawing and drying ($80{ }^{\circ} \mathrm{C}, 0{ }^{\circ} \mathrm{C},+60{ }^{\circ} \mathrm{C}$ and drying) proved to be a really effective technique for killing microarthropods together with oribatid mites. Domes et al. (2007) executed a control experiment in which heating the samples at $60{ }^{\circ} \mathrm{C}$ for 8 weeks destroyed all the microarthropods. Heating treatment for 2,5 hours at $65^{\circ} \mathrm{C}$ is not enough for killing all the Protozoa, fungi and bacteria (Laakso and Setälä, 1999). Freezing at $-20{ }^{\circ} \mathrm{C}$ does not destroy the whole microfauna and all the eggs of microarthropods (Lenoir et al., 2007). Defaunation techniques have some side-effects on soil characteristics e.g. autoclaving increases soil acidity (Liiri et al., 2002), whereas microwaving reduces water holding capacity (Huhta et al., 1989). All the techniques are used in many fields of experiments; there is no standard method for defaunation.

The aim of defaunation is generally to know the refaunated system exactly or to create a new community in accordance with the goals of the study. The composition of communities of microcosm experiments involving intact samples is determined with immediate parallel sampling and extracting (e.g. Lopez et al., 2003). Alternatively, there is no identification because only the control and the treated samples will be compared. These latter examinations are general in studies of human environmental disturbance (e.g. Rantalainen et al., 2004; Heneghan and Bolger, 1996). In further cases knowledge 
of the composition of organismal communities is not important because only biomass is measured after different treatments (Laakso and Setälä, 1999; Taylor et al., 2010).

Defaunation is followed by refaunation by reinoculation of microcosms with organisms. Oribatid mites can be reinoculated into the system in many ways. In arctic and subarctic habitats, some oribatid species can be collected with a single brush because the specimens run on the surface of rocks or cyanobacteria-layer (Sovik and Leinaas, 2003). In most of the cases, specimens are extracted from different soil layers either with Tullgren (Berlese-) funnel or with high-gradient extractor. These methods are used almost in all studies of oribatid mites or microarthropods but for refaunation the animals must be extracted alive. There are several techniques to extract mites alive. The simplest technique is direct extracting when animals are extracted directly from the donor sample into the target sample, i.e. into a (defaunated) microcosm. Intact, original substrates are heated at the top of a funnel or an extractor, while the target substrates are cooled and wetted at the bottom (e.g. Taylor et al., 2010). In this case, we do not know the exact composition of the extracted community but we can evaluate it with parallel communities from the same habitat with retrieving them into alcohol. Microarthropods can be extracted into jars with moist filter papers or water. In this case, animals are placed into microcosms with a brush or the whole filter paper is placed onto the surface of the substrate. Filter papers are left in microcosms for 1-21 days. Large (about $80 \mathrm{~cm} \times 80 \mathrm{~cm}$ ) Tullgren funnels are often applied for such extractions and under the funnels there is a rotating disc with some collecting jars with moist tissue papers. This can assure homogeneous content of jars. If animals are extracted directly into water, they must be transported more often into the microcosms (minimum once a day). Transporting can be made with a brush, a small spoon or with pipette. These extracting techniques are suitable to compose a community with known components at species level (e.g. Laakso and Setälä, 1999). In some experiments, animals are extracted onto moist plaster of Paris and they are stored for some days before reinoculation (e.g. Salminen et al., 1997). Kuperman et al. (2007) used another method for refaunation. They mixed the sulphur mustard polluted, defaunated soil samples with intact homogenized samples.

During extraction larger predator insects and spiders also run into collecting jars. These animals can be dangerous to microarthropods so they are often removed from filter papers or from the water except when the aim of the study is to examine the effects of predators on other organisms (e.g. Schneider and Maraun, 2009). There are some cases when animals should not transport alien microorganisms into the new system so they must be sterilized. A simple technique is to wash mite or worm specimens under tap water (Setälä, 2000) but using streptomycin sulphate is a more effective method (Moore et al., 1985).

The simplest refaunated microcosms contain only the specimens of one or several oribatid mite species in addition to microbiota. In such experiments their tolerance (e.g. Uvarov, 2003), their role in decomposition (e.g. Wickings et al) and their feeding habits (e.g. Crowther et al., 2011a,b) are studied. To get more complex systems, specimens from more taxonomic groups are reinoculated. Microorganisms are reinoculated with soil and water suspension when the knowledge about their exact taxonomic identity is not important in the study. In cases when preparing the suspension is described at all, humus from the collecting place is usually mixed with distilled or tap water ( 15-300 $\mathrm{g}$ humus $\times 1^{-1} 1$ water) then it is sieved with a 5-10 $\mu \mathrm{m}$ mesh and equal portions are added 
to microcosms. Anderson (1978) stored defaunated samples for 10 weeks on forest floor in a mesh which was not permeable for microarthropods.

After microorganisms, nematodes and enchytraeids, finally microarthropods are added to microcosms. In some cases collembola and mites are reinoculated separately. The order and the timing of inoculation vary. In case of direct inoculations, all organisms get the target sample at the same time. In other cases, incubation time is left between inoculations of different animal groups. In the examined studies, the incubation time between the addition of the microorganisms and then microartropods changed between 7-119 days. If there is a planting treatment in the experiment, plants are added to the system either 7-36 days before the microarthropods (e.g. Laakso and Setälä, 1999 ) or e.g. 13 weeks after them (Liiri et al., 2002b). In some studies, nematodes and enchytraeids are inoculated 4-8 days after the microorganisms and 1-2 weeks later microarthropods come to the system (e.g. Sulkava and Huhta, 2003).

Animal abundances applied in these experiments are very variable. In most cases, no explanation is given for values used but there are some studies in which densities are set to the values found under field conditions (e.g. Lenoir et al., 2007). Taylor et al. (2010) applied direct extraction and inoculation because they thought it was important that the rates of animal densities in a microcosm were close to natural.

\section{Incubation}

The second phase of experiments with microcosms is letting the system to work. Durations of examinations are very variable. The shortest ones last only for 7-14 days. Crotty et al. (2011) tracked the flow of ${ }^{13} \mathrm{C}$ and ${ }^{15} \mathrm{~N}$ through soil faunal food web for 11 days, Kuperman et al. (2006) investigated the reaction of soil fauna on mustard gas for 7 days and Anderson (1978) measured the competition between two oribatid mite species for 14 days. Among the longest examinations, there is the complex "macrocosm" study of Huhta and Setälä (1990), in which there were several smaller microcosms in a larger container and densities of different animal groups living in the macrocosms were monitored for 125 days. The second longest experiment was made by Søvik and Leinaas (2003), who investigated the life history of Ameronothrus lineatus Thorell for 21 months. Between the two extreme durations, there are many other applied values. Seven laboratory experiments lasted 7-42 days, twelve examinations lasted 56-98 days, 9 ones lasted 105-180 days and 14 ones lasted 276-875 days.

In a laboratory system, the climate must be set by researchers carefully, usually in a climate chamber. Microcosms without plants are generally kept in darkness but there are some examples when light and darkness change daily even though there is no plant seedling in the microcosm (e.g. Wickings et al., 2011). Temperature is always constant in darkness and it is set commonly between $12-25{ }^{\circ} \mathrm{C}$ but the most often used constant temperature is $15^{\circ} \mathrm{C}$. When plants are also used in microcosms (e.g. Setälä and Huhta, 1991) or intact samples are collected with plants on their surface (e.g. Sjursen et al., 2005), controlling climate in chambers becomes more complex depending on duration. If an examination lasts longer (about $308 \pm 96$ days), seasons also are differentiated even with more than one growing periods (e.g. Liiri et al., 2002b). If complex temperature and lighting periods are not set in microcosm experiments but there are plants in them and diurnal temperatures are constant, the studies last for only short time (e.g. Remén et al., 2010). Unique settings are applied when reactions of soil fauna are investigated under special or extreme temperature circumstances (e.g. Sulkava and Huhta, 2003). 
In most cases, only temperature and light can be controlled automatically in a climate chamber. Suitable water content of microcosms is generally maintained with gravimetric water supplement. That is, the whole microcosm with suitable water content is weighed at the beginning of the experiment and hereafter this weight is maintained. Tap or distilled water is generally added to the system with spraying or just watering and there is a study in which simulated rainwater is applied (Staddon et al., 2010). Watering frequency depends on evaporation. Mini ecosystems kept in constant darkness and temperature are watered commonly once a week but there are water supplements applied more rarely or twice and three times a week. There are some unique solutions: for example, Wickings et al. (2011) elevated the substrates about $5 \mathrm{~mm}$ above water on polypropylene stands in closed jars. Staddon et al. (2010) decreased evaporation by compressing humidified air into the chambers.

During incubation, an essential arrangement is climate control. If the only aim of an experiment is to study the changes of microcosm under given circumstances adjusted at the beginning of the experiment, data will be extracted after the end of the incubation, i.e. microarthropods and other animals will be made run out, abiotic factors will be measured, plant materials will be weighed etc. This method was noted in about $50 \%$ of the examined papers. In the other half of the publications examined by us sampling and even other treatments are applied during incubation. Frequency of sampling was very variable: it was 2-6 times during the incubation and the time between sampling ranged from 6 days to 1 year. In half of the cases, the aim of intermediate sampling was tracking the temporal changes in microcosms. In the other half of the papers, the aim of sampling during incubation was monitoring changes after intermediate treatments. Such treatments can be changing the temperature (e.g. Liiri et al., 2002b), or adding predators and /or herbicide to microcosms (e.g. Salminen et al., 1997).

Sampling design depends on the size of the micro ecosystem. If microcosm size is relatively large, subsamples can be collected (e.g. Domes et al., 2007). In other cases, the experiment includes many smaller parallel microcosms and intermediate sampling means the examination of a whole microcosm (e.g. Andres and Domene, 2005). We reckon measuring abiotic factors during intermediate sampling, i.e. measuring $\mathrm{CO}_{2}$-and nutrient concentration and, if there are plants in the experiments, also plant biomass can be sampled.

\section{Data extraction from microcosms}

The third phase of experiments is extracting information from microcosms. Depending on starting conditions and logistics, there are many opportunities for data extraction. Information related to oribatid mites can be principally acquired with making them run out from the microcosm. In about half of the relevant studies (13 out of 32), Tullgren funnel is applied for extracting microarthropods. The other 19 experiments used high-gradient extractor. In some experiments, samples are divided into subsamples, from which different animal groups are extracted, because the above mentioned techniques are optimal only for mites, since nematodes, enchytraeids and earthworms have different running characteristics.

Taxonomic examination follows extraction. Part of the studies identified oribatid mites at species level but in others mites were classified into microarthropods used as a single variable. The larger part of microcosm experiments ( 24 out of 42 ) with oribatid mites examined the characters of communities or specimens at species level. The other studies relied on family or suborder level. Oribatid mites were examined at species level 
when their tolerance, behaviour, feeding habits, role in decomposition, interactions with other organisms and the effects of pollutants or other human disturbance on them were monitored. At family or suborder level, interest was usually focused on either interactions among microorganisms, soil fauna and plants, or the effects of microhabitat complexity on microarthropods or the role of soil fauna in decomposition processes.

In addition to the taxonomic composition of soil fauna, other factors can be measured in a microcosm experiment. In many cases $\mathrm{pH}$, water content, organic matter content, inorganic N-, C- and P-content of organic soil, humus and litter substrates can be measured. The most often examined ions are $\mathrm{NH}_{4}{ }^{+}$and $\mathrm{NO}_{3}{ }^{-}$. These soil characteristics were measured in $56 \%$ of the studies examined. These values can be compared with changes in community composition and in many cases concentrations of ions and chemicals are monitored during the whole experiment. Maraun et al. (1998) revealed that in presence of oribatid mites leaching of nutrients was greater than in their absence. Nutrients are measured either by mixing water with soil and/or humus samples separately (e.g. Sulkava and Huhta, 2003) or distilled water is made flow over the system and the dissolved ions and other materials can flow through a hole at the bottom of the container into a collecting vessel (e.g. Cole et al., 2004).

Production of $\mathrm{CO}_{2}$ and its changes are often measured in microcosms because these serve important information about the degree of microbial activity through respiration intensity. The most general method for measuring $\mathrm{CO}_{2}$-concentration in microcosms is to sample the atmosphere of the mini ecosystem. Then, the microcosm is sealed hermetically for some hours and sampling is carried out (e.g. with a syringe) before sealing and after sealing and finally the difference is calculated. Besides respiration, there are many methods for measuring biomass of bacteria and fungi. This is important in studies examining oribatid mites since most of them feed on fungi and there are also bacteria feeders (Schneider et al., 2004) and many experiments examine the interactions between microorganisms and oribatid mites (e.g. Kaneko et al., 1998).

If there are plants and/or leaf litter in microcosm experiments, characteristics and changes of animal and microbial communities can be compared with those of plant leaves, roots or shoots: i.e. biomass, water content, $\mathrm{C}-, \mathrm{N}-, \mathrm{K}-\mathrm{Ca}-\mathrm{Mg}$ contents and lignin, tannin, cellulose content (e.g. Katajisto et al., 1999; Wickings et al., 2011).

\section{Summary}

Microcosm experiments extend our knowledge about oribatid mites living in soil by circumventing difficulties arising from their small size and hidden way of life. Most of these studies were performed under laboratory circumstances. It has to be noted, however, that microcosms are artificial systems and the information extracted from them depends on the conditions we made. Therefore, field experiments should be applied parallel to laboratory studies in all cases because without field data we cannot adopt our results to natural conditions (Kampich et al., 2001).

We could see that there are many aspects we have to consider in planning, composing and maintaining a microcosm. If a researcher has decided to find answers to theoretical questions, like in case of other experiments many setting combinations can be chosen. We could also see that in a laboratory microcosm experiments there is no universal rule for selecting a method, the usefulness, validity and limitations of a given technique do not correlate with research objectives. There are many unique solutions and neither of them can always be declared to be the best for our aims. The size of a 
microcosm, the amount of substrate placed in it, abundance and composition of applied animal communities are very variable. We could find many kinds of extraction and incubation methods, experiment duration types and climate chamber settings. Besides this, research issues are very variable so we cannot talk about standardisation with the exception of narrow research fields where the researchers are usually the same (e.g. Sulkava and Huhta, 1998; Sulkava et al., 2001).

Apart from the above difficulties, many useful ideas can be found in other studies. We could see what microcosm experiments can be used for, when only some specimens of a species are studied or when the whole soil community is experimented with. We also saw what kinds of habitats of microarthropods are examined with different manipulations. We could see how a microcosm should be set up; and overviewed the conditions under which the mini ecosystems are kept. We examined how animals can be used for inoculation into defaunated microcosms. If mini ecosystems are ready, then it is important to ensure the natural conditions unless we are interested to see how human impacts modifies microcosm life, this can bring new approaches in the resolution of complex ecological problems (Szlávik and Csete, 2010). In addition, we saw various types of information that can be extracted about the state of microcosms at the end of the experiment.

Acknowledgements. The authors gratefully acknowledges the contribution of Prof. János Podani for his kind linguistic help. This work was supported by the Bolyai János Research Scholarship of MTA Doctoral Council, „ALÖKI” Applied Ecological Research and Forensic Institute Ltd., and the TÁMOP 4.2.1/B-09/1/KMR-2010-0005 project.

\section{REFERENCES}

[1] Adejuyigbe, C.O., Tian, G., Adeoye, G.O. (2006): Microcosmic study of soil microarthropod and earthworm interaction in litter decomposition and nutrient turnover. Nutrient Cycling in Agroecosystems 75(1-3): 47-55.

[2] Anderson, J.M. (1978): Competition between two unrelated species of soil Cryptostigmata (acari) in experimental microcosms. - Journal of Animal Ecology 47(3): 787-803.

[3] Andres, P., Domene, X. (2005): Ecotoxicological and fertilizing effects of dewatered, composted and dry sewage sludge on soil mesofauna: A TME Experiment. Ecotoxicology 14(5): 545-557.

[4] Balogh, P., Gergócs, V., Hufnagel, L., Farkas, E., Farkas, P., Kocsis, M. (2008): Oribatid assemblies of tropical high mountains on some points of the "Gondwana-Bridge" - a case study - Applied Ecology and Environmental Research 6(3): 127-159.

[5] Cole, L. Dromph, K.M., Boaglio, V., Bardgett, R.D. (2004): Effect of density and species richness of soil mesofauna on nutrient mineralisation and plant growth. - Biology and Fertility of Soil 39(5): 337-343.

[6] Crotty, F.V., Blackshaw, R.P., Murray, P.J. (2010): Tracking the flow of bacterially derived ${ }^{13} \mathrm{C}$ and ${ }^{15} \mathrm{~N}$ through soil faunal feeding channels. - Rapid Communications in Mass Spectrometry 25(11): 1503-1513.

[7] Crowther, T.W., Boddy, L., Jones, T.H. (2011a): Species-specific effects of soil fauna on fungal foraging and decomposition. - Oecologia 167(2): 535-545.

[8] Crowther, T.W., Jones, T.H., Boddy, L. (2011b): Species-specific effects of grazing invertebrates on mycelial emergence and growth from woody resources into soil. Fungal Ecology 4(5): 33-341. 
[9] Deere, J.A., Sinclair, B.J., Marshall, D.J., Chown, S.L. (2006): Phenotypic plasticity of thermal tolerances in five oribatid mite species from sub-Antarctic Marion Island. Journal of Insect Physiology 52(7): 693-700.

[10] Drake, J.M., Kramer, A. (2011): Mechanistic analogy: how microcosms explain nature. Theoretical Ecology, DOI: 10.1007/s12080-011-0134-0.

[11] Domes, K., Scheu, S., Maraun, M. (2007): Resources and sex: Soil re-colonization by sexual and parthenogenetic oribatid mites. - Pedobiologia 51(1): 1-11.

[12] Fraser, L.H., Keddy, P. (1997): The role of experimental microcosms in ecological research. - Trends in Ecology and Evolution 12(12): 478-481.

[13] Fujikawa, T. (1999): Individual variations of two reared oribatid species, Tectocepheus velatus (Michael, 1880) and Oppiella nova (Oudemans, 1902). - Edaphologia 62: 11-46.

[14] Gergócs, V., Hufnagel, L. (2009): Application of Oribatid Mites as indicators (Review) Applied Ecology and Environmental Research 7(1): 79-98.

[15] Gergócs, V., Garamvölgyi, Á., Hufnagel, L. (2010): Idication strength of coenological similarity patterns based on genus-level taxon lists. - Applied Ecology and Environmental Research 8(1): 63-76.

[16] Gergócs, V., Garamvölgyi, Á., Homoródi, R., Hufnagel, L. (2011): Seasonal change of oribatid mite comunities (Acari, Oribatida) in three different types of microhabitats in an oak forest. - Applied Ecology and Environmental Research 9(2): 181-195.

[17] Heneghan, L., Bolger, T. (1996): Effects of components of 'acid rain' on the contribution of soil microarthropos to ecosystem function. - Journal of Appl. Ecol. 33(6): 1329-1344.

[18] Huhta, V., Wright, D.H., Coleman, D.C. (1989): Characteristics of soil fauna. I: A comparison of three techniques applied to two different forest soils. - Pedobiologia 33: 417-426.

[19] Huhta, V., Sulkava, P., Viberg, K. (1998): Interactions between enchytraeid (Cognettia sphagnetorum), microarthropod and nematode populations in forest soil at different moistures. - Applied Soil Ecology 9(1-3): 53-58.

[20] Huhta, V. (2007): The role of soil fauna in ecosystems: A historical review. Pedobiologia 50(6): 489-495.

[21] Jonsson, L.M., Dighton, J., Lussenhop, J., Koide, R.T. (2006): The effect of mixing ground leaf litters to soil on the development of pitch pine ectomycorrhizal and soil arthropod communities in natural soil microcosm systems. - Soil Biology \& Biochemistry 38(1): 134-144.

[22] Kaneko, N., McLean, M.A., Parkinson, D. (1998): Do mites and Collembola affect pine litter fungal biomass and microbial respiration? - Applied Soil Ecology 9(1-3): 209-213.

[23] Kampichler, C., Bruckner, A., Kandeler, A. (2001): Use of enclosed model ecosystems in soil ecology: a bias towards laboratory research. - Soil Biology and Biochemistry 33(3): 269-275.

[24] Katajisto, J. Huhta, V., Laakso, J. (1999): Plant effects on the soil community: A microcosm experiment. - European Journal of Soil Biology 35(1): 17-21.

[25] Kuperman, R.G., Phillips, C.T., Checkai, R.T. (2007): Toxicity of chemical warfare agent HD (mustard) to the soil microinvertebrate community in natural soils with contrasting properties. - Pedobiologia 60(6): 535-542.

[26] Laakso, J., Setälä, H. (1999): Sensitivity of primary production to changes in the architecture of belowground food webs. - Oikos 87(1): 57-64.

[27] Lenoir, L., Persson, T., Bengtsson, J., Wallander, H., Wirén, A. (2007): Bottom-up or top-down control in forest soil microcosms? Effects of soil fauna on fungal biomass and C/N mineralisation. - Biology and Fertility of Soils 43(3): 281-294.

[28] Liiri, M., Haimi, J., Setälä, H. (2002a): Community composition of soil microarthropods of acid forest soils as affected by wood ash application. - Pedobiologia 46(2): 108-124.

[29] Liiri, M., Setälä, H., Haimi, J., Pennanen, T., Fritze, H. (2002b): Relationship between soil microarthropod species diversity and plant growth does not change when the system is disturbed. - Oikos 96(1): 137-149. 
[30] Lopez, M.G., Matesanz, M.R., Lidón, J.B.J., Cosín, D.J.D. (2003): The effect of Hormogaster elisae Hormogastridae) on the abundance of soil Collembola and Acari in laboratory cultures. - Biology and Fertility of Soil 37(4): 231-236.

[31] Lopez, M.G., Lidón, J.B.J., Aza, D.T., Rodriguez, M.N., Cosín, D.J.D. (2008): Is there food competition between Hormogaster elisae (Oligochaeta, Hormogastridae) and soil microarthropods at El Molar (Madrid)? - European Journal of Soil Ecol. 44(2): 207-212.

[32] Maraun, M., Visser, S., Scheu, S. (1998): Oribatid mites enhance the recovery of the microbial community after a strong disturbance. - Applied Soil Ecology 9(1-3): 175-181.

[33] Maraun, M., Schatz, H., Scheu, S. (2007) Awesome or ordibary? Global diversity patterns of oribatid mites. - Ecography 30(2): 209-216.

[34] Moore, J.C., Trofymow, J.A., Morley, C.R. (1985): A technique to decontaminate soil microarthropods for introduction to gnotobiotic systems. - Pedobiologia 28(3): 185-190.

[35] Moore, de Ruiter, P.C., Hunt,H.W., Coleman, D.C., Freckman, D.W. (1996): Microcosms and soil ecology: critical linkages between fields studies and modelling food webs. Ecology 77(3): 694-705.

[36] Ojala, R., Huhta, V. (2001): Dispersal of microarthropods in forest soil. - Pedobiologia 45(5): 443-450.

[37] Pernin, C., Ambrosi, J.P., Cortet, J., Joffre, R., Petit, J.L., Tabone, E., Torre, F., Krogh, P.H. (2005): Effects of sewage sludge and copper enrichment on both soil mesofauna community and decomposition of oak leaves (Quercus suber) in a mesocosm. - Biology and Fertility of Soils 43(1): 39-50.

[38] Rantalainen, M.L., Haimi, J., Setälä, H. (2004): Testing the usefulness of habitat corridors in mitigating the negative effects of fragmentation: the soil faunal community as a model system. - Applied Soil Ecology 25(3): 267-274.

[39] Remen, C., Fransson, P., Persson, T. (2010): Population responses of oribatids and enchytraeids to ectomycorrhizal and saprotrophic fungi in plant - soil microcosms. - Soil Biology and Biochemistry 42(6): 978-985.

[40] Salminen, J., Setälä, H., Haimi, J. (1997): Regulation of decomposer community structure and decomposition processes in herbicide stressed humus soil. - Applied Soil Ecology 6(3): 265-274.

[41] Schneider, K., Maraun, M. (2009): Top-down control of soil microarthropods - Evidence from a laboratory experiment. - Soil Biology \& Biochemistry 41(1): 170-175.

[42] Schneider, K., Migge, S., Norton, R.A., Scheu, S., Langel, R., Reineking, A., Maraun. M. (2004): Trophic niche differentiation in soil microarthropods (Oribatida, Acari): evidence from stable isotope ratios (15N/14N). - Soil Biology and Biochemistry 36(1): 1769-1774.

[43] Setälä, H., Huhta, V. (1991): Soil fauna increase Betula pendula growth: laboratory experiments with coniferous forest floor. - Ecology 72(2): 665-671.

[44] Setälä, H. (2000): Reciprocal interactions between Scots pine and soil food web structure in the presence and absence of ectomycorrhiza. - Oecologia 125(1): 109-118.

[45] Siepel, H., Maaskamp, F. (1994): Mites of different feeding guilds affect decomposition of organic matter. - Soil Biology and Biochemistry 26(10): 1389-1394.

[46] Sjursen, H., Michelsen, A., Holmstrup, M. (2005): Effects of freeze-thaw cycles on microarthropods and nutrient availability in a sub-Arctic soil. - Applied Soil Ecology 28(1): 79-93.

[47] Smrz, J. (2006): Microhabitat selection in the simple oribatid community dwelling in epilithic moss cover (Acari: Oribatida). - Naturwissenschaften 93(11): 570-576.

[48] Søvik, G., Leinaas, H.P. (2003): Long life cycle and high adult survival in an arctic population of the mite Ameronothrus lineatus (Acari, Oribatida) from Svalbard. - Polar Biology 26(8): 500-508.

[49] Staddon, P., Lindo, Z., Crittenden, P.D., Gilbert, F., Gonzalez, A. (2010): Connectivity, non-random extinction and ecosystem function in experimental metacommunities. Ecology Letters 13(5): 543-552. 
[50] Sulkava, P., Huhta, V. (1998): Habitat patchiness affects decomposition and faunal diversity: a microcosm experiment on forest floor. - Oecologia 116(3): 390-396.

[51] Sulkava, P., Huhta, V., Laakso, J., Gylén, E.R. (2001): Influence of soil fauna and habitat patchiness on plant (Betula pendula) growth and carbon dynamics in a microcosm experiment. - Oecologia 129(1): 133-138.

[52] Sulkava, P., Huhta, V. (2003): Effects of hard frost and freeze-thaw cycles on decomposer communities and $\mathrm{N}$ mineralisation in boreal forest soil. - Applied Soil Ecology 22(3): 225-239.

[53] Szlavik, J., Csete, M. (2010): Climate change and economics of rehabilitation and reconstruction. Chapter 20. - In: Climate Change and Hungary: Mitigating the Hazard and Preparing for the Impacts (The „VAHAVA” Report). (Farago, T., Lang, I., Csete, L. eds.) Budapest, 2010. ISBN 978-963-508-605-4 (pp.109-114)

[54] Taylor, A.R., Pflug, A., Schröter, D., Wolters, V. (2010): Impact of microarthropod biomass on the composition of the soil fauna community and ecosystem processes. European Journal of Soil Biology 46(2): 80-86.

[55] Wickings, K., Grandy, A.S. (2011): The oribatid mite Scheloribates moestus (Acari: Oribatida) alters litter chemistry and nutrient cycling during decomposition. - Soil Biology and Biochemistry 43(2): 351-358.

[56] Uvarov, A.V. (2003): Effects of diurnal temperature fluctuations on population responses of forest floor mites. - Pedobiologia 47(4): 331-339.

[57] Wallwork, J.A. (1983): Oribatids in Forest Ecosystems. - Annual Review of Entomology 28: 109-130. 